\title{
Estudo de caso em uma empresa de gestão de resíduos sólidos da construção civil no município de campos dos Goytacazes-RJ
}

\section{Case study in a solid waste management company in the municipality of campos dos Goytacazes-RJ}

DOI: $10.46814 /$ lajdv3n3-043

Recebimento dos originais: 01/052021

Aceitação para publicação: 31/06/2021

\author{
Camila Mendonça Romero Sales \\ Doutora em Engenharia e Ciência dos Materiais \\ Instituto Federal Fluminense Campus Campos Centro \\ R. Dr. Siqueira, No 273 - Parque Dom Bosco, Campos dos Goytacazes - RJ, 28030-130 \\ E-mail: camila.sales@iff.edu.br \\ Caio Victor Melo Lopes \\ Bacharel em Engenharia de Produção \\ Universidade Candido Mendes - Campos \\ Av. Anita Peçanha, № 100 - Parque São Caetano, Campos dos Goytacazes - RJ, 28030-335 \\ E-mail: caio_victor_melo@hotmail.com

\section{Renato Ribeiro da Silva} \\ Bacharel em Engenharia de Produção \\ Universidade Candido Mendes - Campos \\ Av. Anita Peçanha, No 100 - Parque São Caetano, Campos dos Goytacazes - RJ, 28030-335 \\ E-mail: renatoriber@gmail.com

\section{Diego da Silva Sales} \\ Doutor em Engenharia e Ciência dos Materiais \\ Instituto Federal Fluminense Campus Campos Guarus \\ Av. Souza Mota, No 350 - Parque Fundão, Campos dos Goytacazes - RJ, 28060-010 \\ E-mail: dsales@iff.edu.br
}

\section{RESUMO}

Atualmente a consciência sustentável tanto das empresas quanto dos clientes tem levado as companhias a adotar atitudes que preservem a natureza, o que faz com que elas se tornem altamente competitivas de forma a superar seus concorrentes no mercado. Diante dessa nova visão, a prática dos 3R`s (Reduzir, Reutilizar e Reciclar) nas empresas tem se tornado uma saída para a resolução de problemas ambientais. O estudo de caso proposto neste trabalho idealiza a viabilidade de trabalhar, investir no reaproveitamento de resíduos e obter lucro com essa prática sustentável. Foram realizadas visitas a uma empresa responsável pelo transporte, reciclagem e destinação dos resíduos sólidos de uma forma em geral, tendo como foco a área da construção civil. Foi estudado o mercado da construção civil no município de Campos dos Goytacazes com relação aos resíduos gerados. Os resultados obtidos mostram de uma forma geral, que as empresas têm consciência ecológica no que se refere a questão da sustentabilidade, todavia existe uma distância significativa entre teoria e prática. Um dos principais motivos para não se praticar esse correto gerenciamento é a falta de fiscalização por partes dos órgãos públicos, que faz com que os empresários da região não atuem de acordo com as legislações ambientais. A conclusão desse estudo aborda a viabilidade e a necessidade da instalação de uma usina de 
reciclagem de RCD no município, em face ao grande desenvolvimento da região, o que na prática conseguiria atenuar o cenário de degradação que atinge não somente o município, como todo o país.

Palavras-chave: Construção Civil, Sustentabilidade, Resíduos Sólidos.

\begin{abstract}
Currently, the sustainable awareness of both companies and customers has led companies to adopt attitudes that preserve nature, which makes them highly competitive in order to overcome their competitors in the market. Given this new vision, the practice of the 3R's (Reduce, Reuse, Recycle) in companies has become a way to solve environmental problems. The case study proposed in this paper idealizes the feasibility of working, investing in the reuse of waste and obtaining profit from this sustainable practice. Visits were made to a company responsible for the transportation, recycling and disposal of solid waste in general, focusing on the civil construction area. The civil construction market in Campos dos Goytacazes was studied in relation to the waste generated. The results obtained show, in general, that the companies are ecologically aware with regard to the issue of sustainability; however, there is a significant gap between theory and practice. One of the main reasons for not practicing this correct management is the lack of inspection by public agencies, which makes businessmen in the region not act in accordance with the environmental laws. The conclusion of this study addresses the feasibility and the need for the installation of a recycling plant of CDW in the city, given the great development of the region, which in practice could mitigate the scenario of degradation that affects not only the city, but the whole country.
\end{abstract}

Keywords: Civil Construction, Sustainability, Solid Waste.

\title{
1 INTRODUÇÃO
}

O setor de construção é um dos setores mais antigos da indústria, cuja terminologia é utilizada para denominar obras de construções de casas, prédios, estradas, aeroportos e infraestruturas em geral. Com o crescimento desse setor, aumenta a geração de resíduos sólidos de forma excessiva, proveniente das construções.

O planeta não admite o consumo desorganizado dos materiais, pois os recursos são finitos, logo é preciso se conscientizar de que o consumo tem que obedecer a um aspecto de sustentabilidade.

Neste contexto, a cada dia que passa o ser humano tem que saber da sua necessidade em usar e descartar produtos e resíduos de maneira correta, não só por conta dos efeitos negativos que os mesmos causam no meio ambiente pela sua deposição incorreta, mas também como forma de adquirir retornos financeiros com o seu reaproveitamento. Diante desse cenário o presente estudo busca avaliar como as empresas do mercado da construção civil em Campos dos Goytacazes têm feito para descartar e reaproveitar esses materiais.

A prática da logística reversa é uma ferramenta que pode ser utilizada nas empresas para amenizar os impactos negativos causados pelo excesso de resíduos gerados do setor. Além de ser uma ação sustentável pelo qual se consegue fazer o reaproveitamento de partes dos materiais utilizados nos 
processos e descartar de forma correta aqueles que não podem ser reutilizados. Um exemplo dessa prática é a empresa em estudo nesse trabalho, que atua no mercado da região Norte-Fluminense com algumas parcerias que envolvem o reaproveitamento e descarte dos resíduos da construção civil da maneira correta.

\section{CONSTRUÇÃO CIVIL E SUA EXPANSÃO}

Segundo Denascy (2013), a construção civil é considerada uma das áreas mais antiga da indústria, na qual trabalham engenheiros, arquitetos, técnicos, operários etc. Os seguintes termos: construção civil e engenharia civil, são originados de uma época em que só existiam apenas duas classificações para a engenharia, são elas: engenharia militar e engenharia civil, em que a militar era para os militares da época e a civil era para os outros cidadãos que englobava todas as outras áreas. Com o passar do tempo foi dividida, hoje em dia existem 35 engenharias.

Segundo dados que foi divulgado pelo Instituto Brasileiro de Geografia e Estatística (IBGE), o Produto Interno Bruto (PIB) da Construção Civil cresceu 1,4\% em 2012. Em 2011 o resultado da Construção civil foi o segundo melhor da Indústria, ficou atrás apenas do setor de produção e distribuição de eletricidade, gás, água, esgoto e limpeza urbana (3,6\%) (CÂMARA BRASILEIRA DA INDÚSTRIA DA CONSTRUÇÃO, 2013).

O cenário atual na indústria da construção civil é um grande número de obras espalhadas por todo país devido aos acontecimentos que ocorrerão como, a Copa do Mundo e os Jogos Olímpicos. Com isso a procura pelo curso de engenharia civil foi de 75.881 matrículas em 2009, segundo o Instituto Nacional de Estudos e Pesquisas Educacionais (INEP), devido a esses grandes eventos o país vai ter que reformar e construir hotéis, estádios, estradas, aeroportos entre outras instalações (GUIA DO ESTUDANTE, 2011).

A falta de profissionais treinados, segundo estudo realizado pela Fundação Getúlio Vargas (2011) acarreta uma valorização nos trabalhadores que são qualificados na área de construção civil, em que a remuneração para esses profissionais cresceu $26 \%$ em média nos últimos anos. O resultado disso é uma grande procura nas universidades pelo curso de engenharia civil no Brasil.

\subsection{RESÍDUOS DA CONSTRUÇÃO CIVIL}

Segundo Carvalho e Vasconcelos (2010) o setor de produção que mais desperdiça os recursos naturais durante seu processo é o da construção civil. Isso ocorre devido a um processo de construção ineficaz provocado por falhas de projetos, má qualidade dos materiais utilizados, conservação inadequada, transporte incorreto, falhas durante a sua execução, mão de obra sem qualificação entre outros. Os entulhos da construção civil têm origem em quase todos os materiais que sobram do processo 
produtivo como: areia, concretos, plásticos, papéis, tintas, metais, madeira, argamassa, tijolos, pedras, etc. A disposição final dos entulhos de maneira inadequada gera riscos ambientais e sanitários para a população. Os riscos são: contaminação do solo e da água, enfermidade por poluentes químicos que geram também problemas como: desvalorização de áreas, desperdício de materiais e energia, ruídos, poeira, etc.

Para Zordan (2001, apud CARVALHO; VASCONCELOS, 2010) o entulho como já foi citado é formado em diferentes características, dependem do tipo de construção, práticas utilizadas e também pela fase que se encontra a construção. De acordo com Carvalho e Vasconcelos (2010), os três tipos de obras que dão origem ao entulho são: construções na qual os materiais se apresentam em estado que não foi utilizado em nenhuma fase; reformas e demolições em que encontramos materiais na sua forma final, como concreto armado, piso revestido e paredes de alvenarias, etc.

De acordo com Medeiros et al. (2012), o impacto negativo que a construção civil causa no meio ambiente é preocupante, com isso se torna necessário que as empresas se conscientizem e crie soluções para minimizar esse problema, pois nos dias atuais os consumidores buscam por produtos e serviços

que sejam produzidos de maneira social, responsável e ambientalmente correto. É importante que as empresas visualizem essa necessidade como uma oportunidade de mercado, pois deve saber que ações de responsabilidade social, política e prática ambiental são investimentos que geram lucros futuros e cria vantagem competitiva. Isso se torna um fator diferencial.

\subsection{LEGISLAÇÃO VIGENTE DA CONSTRUÇÃO CIVIL}

De acordo com Carvalho e Vasconcelos (2010) os resíduos da construção civil propriamente dito não representam grandes riscos ambientais. Contudo muitas cidades brasileiras sofrem impactos ambientais provocados pela intensa deposição irregular de resíduo da construção e demolição (RCD). No ano de 2002, teve início no Brasil o estabelecimento de políticas públicas voltadas para a indução da implantação de áreas para o manejo sustentável de tal resíduo, que foi a resolução 307/02 Conselho Nacional do Meio Ambiente (CONAMA).

Segundo Wiens e Hamada (2006) as legislações ambientais existente no país que regulamentam a construção civil são: Resolução do CONANA; Constituição Federal de 1988; Associação Brasileira de Normas Técnicas (ABNT) publicou cinco normas relacionadas aos RCD's que servem para nortear o seu plano de gerenciamento quais sejam:

NBR 15112:2004 - área de trasbordo e triagem.

NBR 15113:2004 - diretrizes para projeto, implantação e operação de aterros.

NBR 15114:2004 - diretrizes para projeto, implantação e operação de áreas de reciclagem. 
NBR 15115:2004 - procedimentos para execução de camadas de pavimentação utilizando agregados reciclados de resíduos da construção.

NBR 15116:2004 - requisitos para utilização em pavimentos e preparo de concreto sem função estrutural com agregados reciclados de resíduos da construção.

Segundo Marques Neto (2005, apud WIENS; HAMADA, 2006) calcula-se que para cada tonelada de lixo recolhido, são recolhidas duas toneladas de entulho. Esses resíduos são provenientes em sua maioria das obras civis que incluem construções e demolições, terraplanagens e manutenção.

\subsection{COMPARATIVO ENTRE RIO DE JANEIRO E CAMPOS DOS GOYTACAZES}

O estado do Rio de Janeiro tem como instrumento da política de resíduos o programa RECICLA-RIO, em que o mesmo está contido dentro do Plano Estadual de Resíduos Sólidos (PERS). Este programa busca a valorização dos resíduos sólidos e formação de parcerias entre os setores públicos, privados e comunitários, como objetivo de intensificar as iniciativas de reciclagem dos resíduos produzidos no estado do Rio de Janeiro, com foco no fluxo reverso dos resíduos gerados (GOVERNO DO ESTADO DO RIO DE JANEIRO, 2013). Outro projeto adotado pelo estado é o entulho limpo na baixada (ELB), em que seis municípios da região metropolitana são atendidos. Entre eles cita-se: Belford Roxo, Duque Caxias, Mesquita, Nilópolis, Nova Iguaçu e São João de Meriti.

Já no município de Campos dos Goytacazes, o órgão que cuida desta parte é a secretaria Municipal de Serviços Público em parceria com a secretaria de Meio Ambiente, que tem como serviço o ponto de entrega voluntária de entulhos (PEVE) visto na figura 12. Normalmente esses PEVE`s são construídos em terrenos de $900 \mathrm{~m}^{2}$ em média, espalhado em vários bairros da cidade destinado ao recebimento de resíduos da construção civil, oriundo de pequenas construções, demolições e reformas (PREFEITURA MUNICIPAL DE CAMPOS DOS GOYTACAZES, 2013). Outro serviço é o disque entulho, na qual faz a coleta de pequenos resíduos armazenados dentro das residências e devidamente acondicionados de acordo com a sua quantidade. O destino dado a esses resíduos é Central de Triagem de Resíduos Sólidos e Compostagem do distrito de Santo Amaro (Usina de Santo Amaro), que está localizada na sede do distrito com capacidade de receber 30 t/dia e fazer a triagem de 15 a 17 t/dia de resíduos. Existe também na cidade o plano de gerenciamento de resíduos sólidos (PGRS), obrigatório a empresas industriais, comerciais, da construção civil ou de prestação de serviços e outras empresas que estão sujeitas a agredir o meio ambiente, como exemplo, postos de gasolina (PREFEITURA MUNICIPAL DE CAMPOS DOS GOYTACAZES, 2013). O objetivo desse plano é contribuir para a redução dos resíduos sólidos no município e orientar o acondicionamento, armazenamento, tratamento, coleta, transporte e por fim a destinação final. 


\section{CONSIDERAÇÕES}

Através dos resultados obtidos durante as investigações em campo, em relação ao tratamento e gerenciamento dos resíduos da construção civil, pôde-se observar que a maioria das empresas faz utilização de caçambas estacionárias metálicas, próxima a geração do resíduo, para seu acondicionamento temporário. Todavia em contato com uma empresa que realiza o aluguel das caçambas, para depois transporte e destinação final em aterro da Companhia de Desenvolvimento Industrial do Estado do Rio de Janeiro (CODIN), não foi evidenciado nenhum tipo de licença ambiental por um órgão responsável. Entretanto em algumas situações, o RCD gerado não passa pela etapa do acondicionamento temporário em caçambas e este é destinado em áreas supostamente clandestinas, inclusive em áreas centrais e urbanas sem nenhuma autorização por parte de prefeitura.

Para o município de Campos dos Goytacazes, estima-se uma produção mensal de $34.000 \mathrm{~m}^{3}$ de $\mathrm{RCD}$, valor obtido em função do controle de veículos que descarregam nas dependências do aterro controlado da (CODIN), desconsideram-se os pontos de despejo clandestinos. Desses materiais descartados, uma parte considerável é constituída de produtos inertes como argamassas, concretos e telhas, possíveis de serem reciclados. Além disso, ainda observa-se em determinadas obras prediais, misturas de resíduos em geral, como classificados como perigosos e RCD, o que atrapalha, ainda mais uma possível separação na fonte de geração. Uma maior qualificação dos profissionais ajudaria amenizar essa situação.

A figura 1 mostra a quantidade média de funcionários nas empresas visitadas. Esses números são relativos às empresas de pequeno e médio porte, que foi uma característica encontrada na região.

Figura 1 - Números de Funcionários das Empresas.

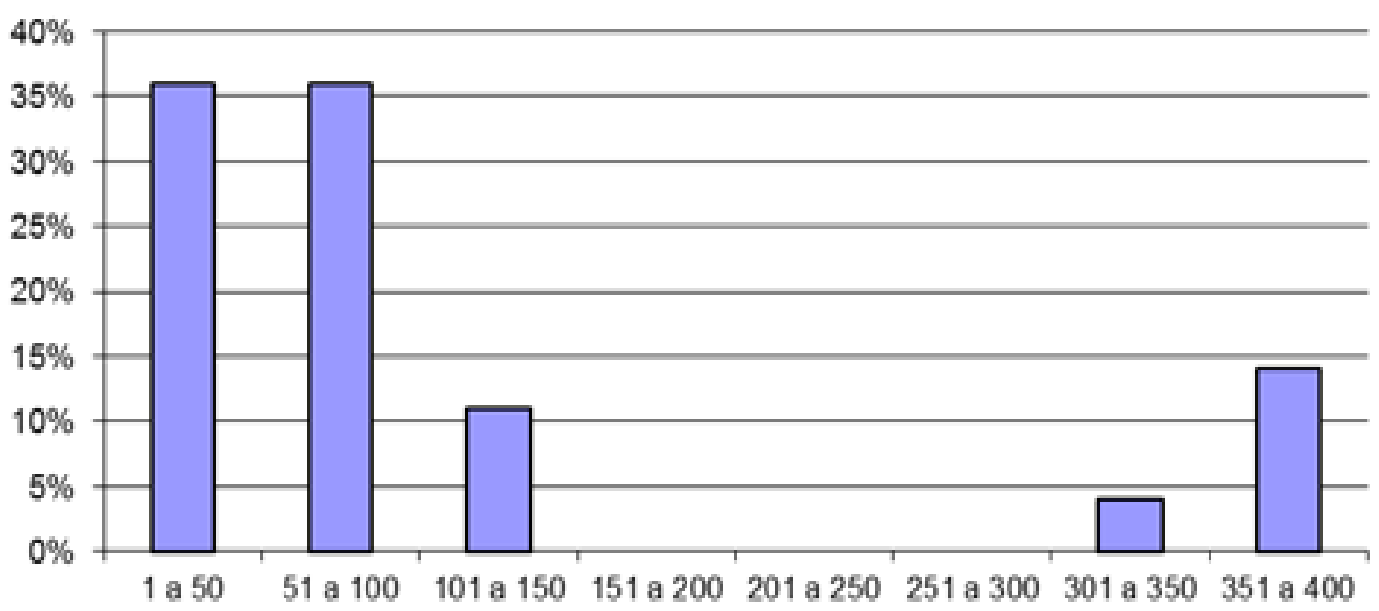


A figura 2 (a) ilustra a quantidade média de obras que estão em andamento, uma característica observada foi que apesar das empresas serem de pequeno e médio porte, todas estão com mais de uma obra em andamento. Já na figura 2 (b) pode ser visualizado que a maioria dos entrevistados possui bom nível de conhecimento sobre a prática do gerenciamento de resíduos, isso se torna um fator positivo para o processo.

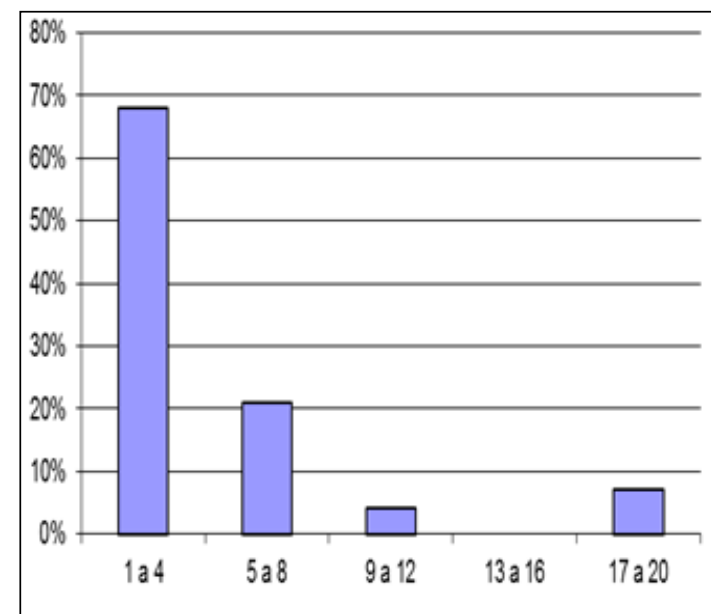

2 (a)

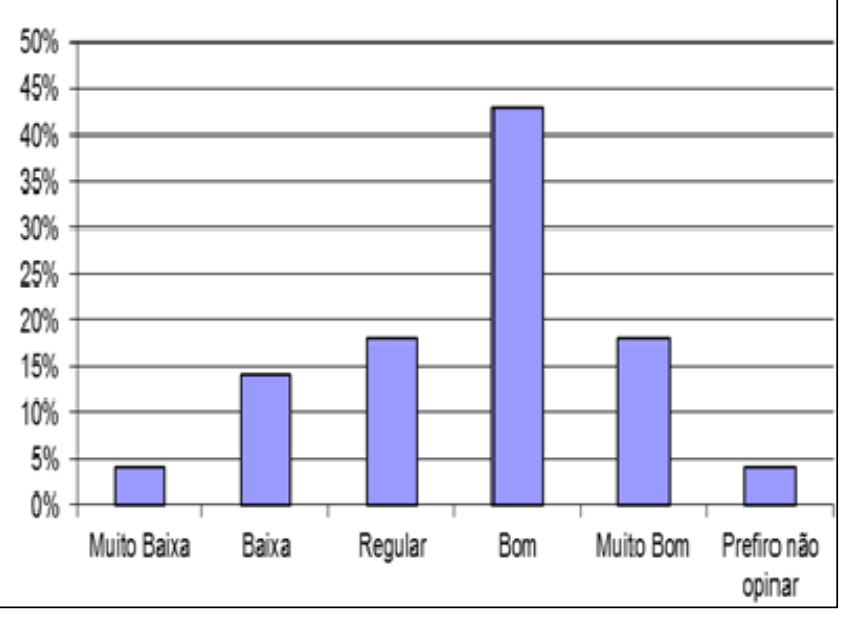

2 (b)

Na figura 3 (a) é mostrado o número de obras em andamento nas empresas que praticam o gerenciamento de resíduos. A figura 3 (b) é observado o motivo por não praticar o gerenciamento de resíduos, nota-se que a falta de empresas que atuam no ramo é fator principal para não praticar o gerenciamento de forma correta. A 3 (c) indica que a maioria dos entrevistados tem a preocupação com o meio ambiente como principal motivo para se praticar o gerenciamento de resíduo.

Pode ser visualizado o quanto se gasta em média com o recolhimento do resíduo, que geralmente é feito através de caçambas estacionárias metálicas (broocks), que acondicionam temporariamente os entulhos no seu local de geração, através da figura 3 (d). Assim como é evidenciado o motivo pela falta de atitude pró-ativa dos empresários do ramo no que se refere ao gerenciamento de resíduo 3 (e). Existe uma falha no sistema (Fiscalização), em que alguns empresários revelam que não são submetidos a nenhum tipo de punição por não se praticar o correto gerenciamento de resíduos em suas obras.

O grau de importância das empresas pela sustentabilidade na hora da venda do seu produto é regular, visualizado na figura 3 (f), pois apesar da consciência sustentável, poucos são aqueles que estão dispostos há pagar um pouco mais por produtos/serviços ecologicamente corretos. 


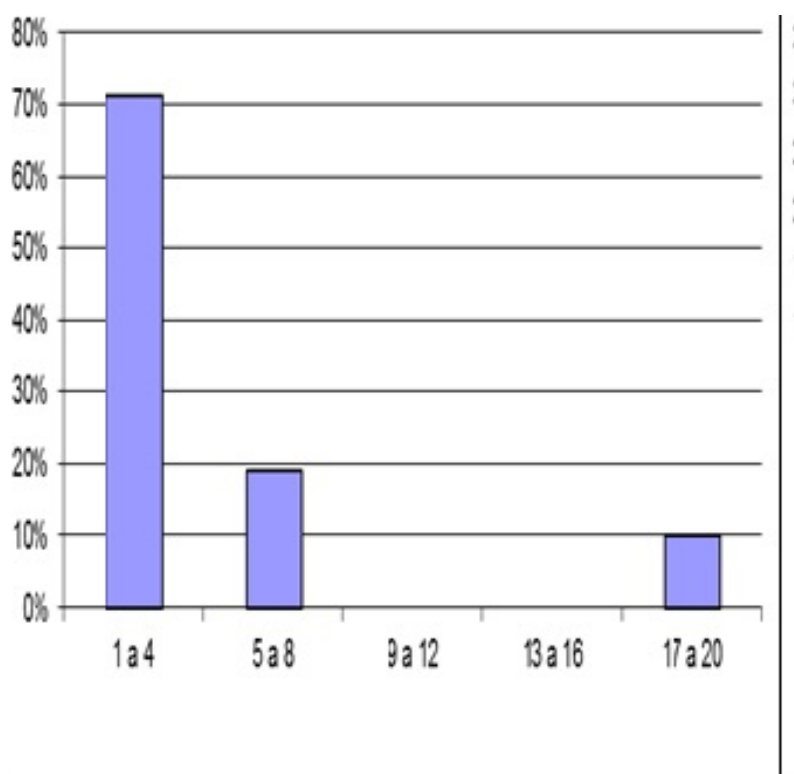

3 (a)

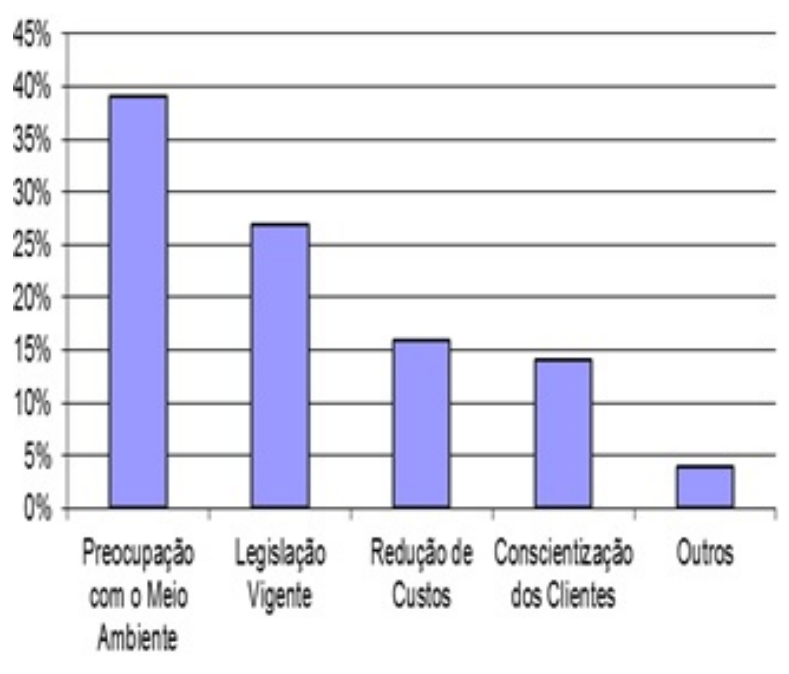

$3(\mathrm{c})$

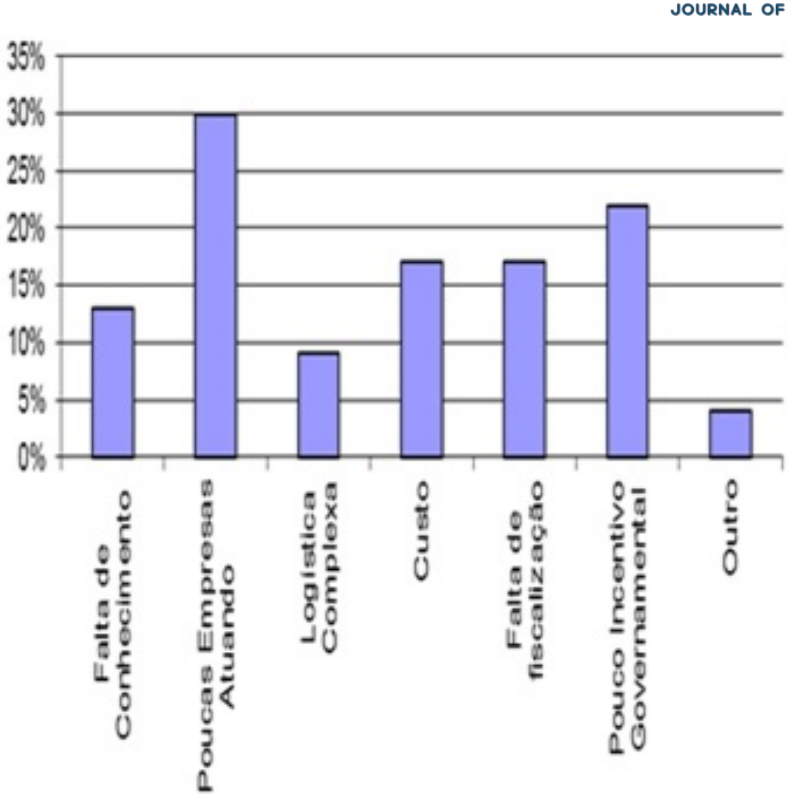

3 (b)

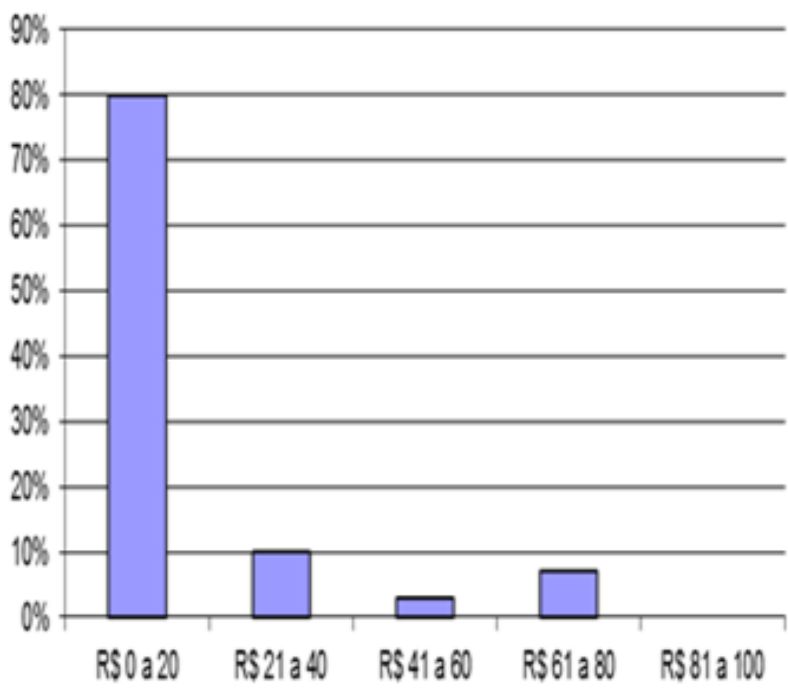

$3(d)$ 


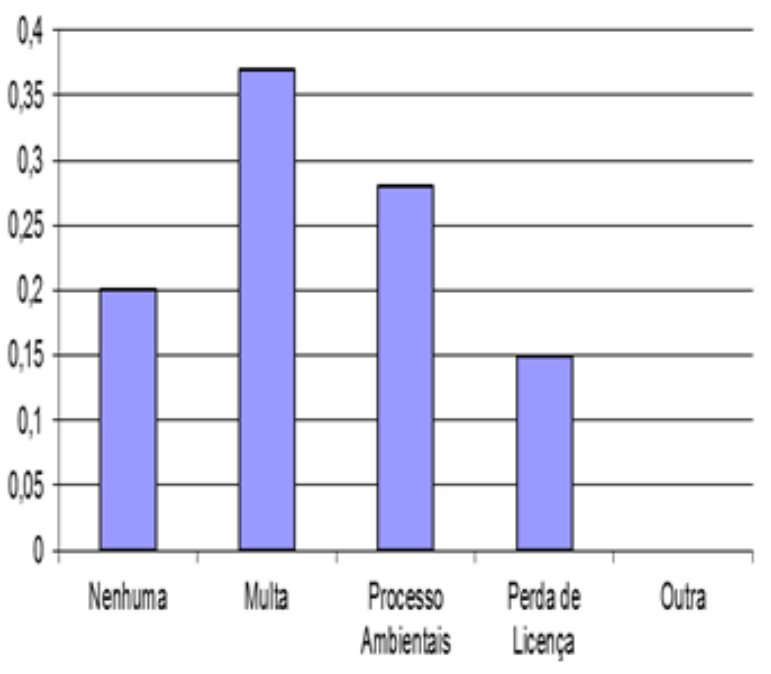

$3(\mathrm{e})$

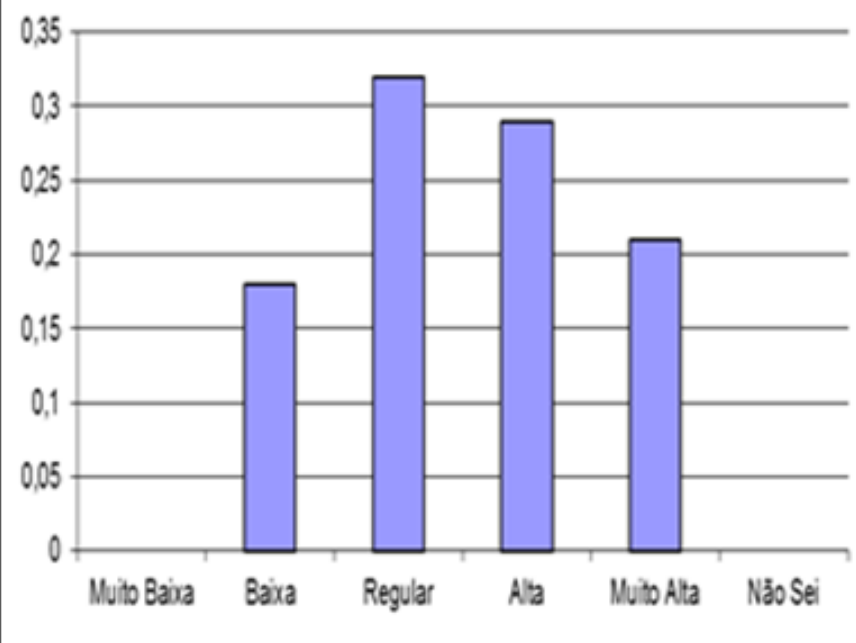

$3(\mathrm{f})$

Foi observado com a realização da pesquisa, que existem vários empreendimentos de edificações no município, seja de condomínios residenciais e edificações comerciais entre outros. Essas obras situam-se nas áreas urbanas, principalmente. Outra observação é o número expressivo de construtoras e empresas de engenharia que atuam nesse setor. Diante desse estudo, foi constatada através de visitas realizadas nos escritórios das empresas, certa conscientização teórica do assunto (sustentabilidade na construção civil), mas na prática foi observado algo diferente, pois existe um número considerável de empresas que desconhecem a destinação final do resíduo após a coleta. Foi identificado que um dos principais motivos pela não prática do gerenciamento, é além de outros, a falta de empresas que atuam nesse segmento. Outro ponto observado, com a realização da pesquisa foi à contradição visualizada juntamente aos empresários da região, quando questionados sobre os motivos da prática do correto gerenciamento de resíduos. Os dados mostram uma preocupação com a preservação do meio ambiente, em contra partida observa-se poucas práticas que verdadeiramente demonstram essa preocupação, em que a maioria apenas transfere o problema para outros, algo que foi evidenciado no questionamento dado aos resíduos após a coleta, pois muitos desconhecem. A falta de fiscalização no setor é um fator que faz com que os empresários da região atuem de forma irregular no gerenciamento dos seus resíduos. Essa ausência traz consigo a impunidade, em que nada acontece com aqueles que destinam os RCD`s em áreas inadequadas, muitas vezes realizados por serviços de carroceiros.

Segundo Bittencourt e Jungles (2012) um estudo realizado no setor de edificações da grande Florianópolis, foi constatado que apesar da existência da consciência ambiental por parte das empresas, há um pequeno comprometimento no que se refere á implementação do sistema de gerenciamento ambiental nas obras. Foi constatado a dificuldade de se adequar os canteiros de obras das empresas, foi 
verificado também que na cidade de Campos dos Goytacazes ocorre o mesmo problema por fatores similares, como por exemplo, a falta de mão de obra qualificada nos canteiros, o que proporciona uma dificuldade para iniciar o gerenciamento dos resíduos no seu local de geração. Outro ponto observado foi que existem muitas obras em andamento na cidade, principalmente na área urbana, que tem provocado um crescimento desordenado. Esse quantitativo de obras gera uma expressiva quantidade de entulho, na qual muitas empresas não sabem o local de destinação final. Esse resíduo poderia ser melhor gerenciado, se dentro dos canteiros de obra existissem políticas voltadas para a prática do gerenciamento e da logística reversa dos resíduos.

Conclui-se que existe possibilidade técnica, ambiental e econômica para a instalação de uma usina de reciclagem de RCD no município de Campos dos Goytacazes-RJ, para que isso aconteça é preciso que haja uma ação conjunta entre órgãos públicos, empresas e representantes do setor de construção, além de instituições de pesquisa como a UCAM, UENF, IFF entre outros. Uma cidade do porte de Campos dos Goytacazes possui profissionais e empresas capazes de desenvolver este programa, cita-se como exemplo a empresa em estudo nesse trabalho: que faz a coleta, transporte e destinação de tais resíduos, uma síntese do processo da logística reversa. Essa prática consegue reverter o que atualmente são custos para os cofres públicos, e ao mesmo tempo, a empresa consegue obter lucro com o seu trabalho. 


\section{REFERÊNCIAS BIBLIOGRÁFICAS \\ REFERENCIAS BIBLIOGRÁTCAS}

BITTENCOURT, M.; JUNGLES, A.E. Diagnóstico de Responsabilidade Ambiental no Processo de Execução de Obras de Empresas Construtoras de Micro, Pequeno e Médio Porte. In: Anais ENEGEP, 2012, XXXII, Bento Gonçalves RS. Internet. Disponível em:

http://www.abepro.org.br/biblioteca/enegep2012_TN_STO_165_959_19504.pdf. Acesso em: 14 mar. 2013.

CARVALHO, M.E.H.P; VASCONCELOS, S.S. Gestão de Projeto de Reaproveitamento dos Entulhos de Concreto Gerados Pela Construção Civil. In: Anais ENEGEP, XXX, 2010, São Carlos SP. Disponível em:

http://www.abepro.org.br/biblioteca/enegep2010_TN_STP_120_783_15856.pdf. Acesso em: 20 mar. 2013.

CÂMARA BRASILEIRA DA INDÚSTRIA DA CONSTRUÇÃO. Construção Civil cresce 1,4\% em 2012. [S. 1.], 2013. Disponível em: http://www.cbicdados.com.br/menu/home/construcao-civil-cresce14-em-2012. Acesso em: 20 mar. 2013.

GOVERNO DO ESTADO DO RIO DE JANEIRO. Disponível em: http://www.rj.gov.br//. Acesso em: 02 ago. 2013.

GUIA DO ESTUDANTE. Disponível em: http://guiadoestudante.abril.com.br/profissoes/engenhariaproducao/construcao-civil-684655.shtml. Acesso em: 04 mar. 2013.

MEDEIROS, H.R.D. de et al. Utilização de Eco-Enovações como Ferramenta de Gestão de Recursos Naturais na Construção Civil. In: Anais ENEGEP, XXXII, 2012, Bento Gonçalves RS. Internet. Disponível em: http://www.abepro.org.br/biblioteca/enegep2012TN_STO_165_959_19463.pdf. Acesso em: 20 mar. 2013.

PREFEITURA MUNICIPAL DE CAMPOS DOS GOYTACAZES. Disponível em: <http://www.campos.rj.gov.br>. Acesso em: 02 ago. 2013.

DENASCY CONSTRUÇÕES: HISTÓRIA DA CONSTRUÇÃO CIVIL NO BRASIL. Internet. Disponível em:

http://www.denascyconstrucoes.com.br/index.php?option=com_content\&view=article\&id=21\&Itemi $\mathrm{d}=54$. Acesso em: 22 mar. 2013.

WIENS, I.K.; HAMADA, J. Gerenciamento de Resíduos da Construção Civil - Uma Introdução a Legislação e Implantação. In: Anais SIMPEP, XIII, 2006, Bauru SP. Internet. Disponível em:

http://www.simpep.feb.unesp.br/anais/anais_13/artigos/374.pdf. Acesso em: 16 mar. 2013. 